\title{
The final stage of the laparoscopic procedure: exploring final steps
}

Ricardo A. Natalin, Fabio S. Lima, Thomé Pinheiro, Eugenio Vicari, Valdemar Ortiz, Cassio Andreoni, Jaime Landman

Universidade Federal de Sao Paulo (RAN, FSL, TP, EV, VO, CA,) Sao Paulo, Brazil and Columbia University Medical Center (RAN, JL), New York, USA

\section{ABSTRACT}

Despite significant advances in laparoscopic technique and technologies, laparoscopic Urologic surgery remains technically demanding regarding various surgical steps including the challenge of specimen retrieval and extraction, whether to install a drainage system and the best option for wound closure. Laparoscopic specimen entrapment and extraction occurs at what is falsely considered the "end of the procedure". During open surgery, after the specimen has been mobilized, the specimen is simply lifted out of the larger incision which has been made to achieve the surgical objectives. In contrast, significant laparoscopic skill is required to entrap and safely extract laparoscopic specimens. Indeed, the Urologist and surgical team which are transitioning from open surgery may disregard this important part of the procedure which may lead to significant morbidity. As such, it is imperative that during laparoscopic procedures, the "end of the procedure" be strictly defined as the termination of skin closure and dressing placement. Taking a few minutes to focus on safe specimen entrapment and extraction will substantially reduce major morbidity. The following review focus on the technology and technique of specimen entrapment and extraction, on the matter of whether to install a drainage system of the abdominal cavity and the options for adequate closure of trocar site wounds. This article's primary objectives are to focus on how to minimize morbidity while maintain the advantages of a minimally invasive surgical approach.

\section{ARTICLE INFO}

\author{
Key words: \\ Laparoscopy; urology; kidney; \\ outcomes
}

Int Braz J Urol. 2012; 38: 4-16

Submitted for publication:

March 21, 2011

Accepted after revision:

July 14, 2011

\section{INTRODUCTION}

Urologic surgery continues to evolve focusing efforts on adequate treatment of pathologic urologic conditions in a safe and minimally invasive manner (1).

Laparoscopic surgery has well defined benefits for the patient and has, over time, become accepted as a standard of care access strategy for the management of benign and malignant Urologic diseases.
Despite significant advances in laparoscopic technique and technologies, laparoscopic Urologic surgery remains technically demanding. Unlike open surgery, at the end of laparoscopic extirpative procedures, the Urologist is often faced with the additional challenges of specimen retrieval and extraction.

Laparoscopic specimen entrapment and extraction occur at what is falsely considered the "end of the procedure". During open surgery, after the specimen has been mobilized, the specimen is 
simply lifted out of the larger incision which has been made to achieve the surgical objectives. At this time the open surgical team is typically more relaxed, and may turn up the volume on what is commonly referred to as "closing music".

In contrast, significant laparoscopic skill is required to entrap and safely extract laparoscopic specimens. Indeed, the Urologist and surgical team which are transitioning from open surgery may disregard this important part of the procedure which may lead to significant morbidity. As such, it is imperative that during laparoscopic procedures, the "end of the procedure" be strictly defined as the termination of skin closure and dressing placement.

The following review will focus on the technology and technique of specimen entrapment, extraction, and drainage of the abdominal cavity for safely exiting the abdomen. This article's primary objectives are to focus on how to minimize morbidity while maintaining the advantages of a minimally invasive surgical approach.

\section{Entrapment and retrieval devices}

Important characteristics to be evaluated in a retrieval device are the sack permeability, resistance and sack stability inside the abdominal cavity (2). Clinical application of specimen retrieval devices requires some characteristics in order to enable surgical manipulation and safety. The device needs to be easily handled from trocar insertion, sack visibility, opening, closure and removal.

A variety of different retrieval devices are commercially available, each one presenting particular characteristics as show in Table-1.

Several technologic improvements have been made regarding the retrieval devices like the use of impermeable sack, used for both intact and fragmented specimen removal. The impermeable sack improves safety regarding port-site recurrence as this rare but serious complication has been reported after organ retrieval without protection. (3).

Cytologic washings from intact specimen retrieval devices sacks revealed that low-stage, low-grade tumors after minimal manipulation do not exfoliate cells into the retrieval sack. Howev- er, higher grade and staged tumors may present different outcomes regarding cell exfoliation and should be properly treated (4).

Recently Ganpule et al. described a new entrapment and retrieval device, arguing it to be effective and with a lower cost, the Nadiad Bag. The bag is manually constructed by the use of a 5F ureteral catheter (Devon Industries, Bangalore, India), a nylon thread and a polyethylene bag (Steribag, PCI, Kandivali, Mumbai, India); the bag is sealed at one end with an autoseal device (Rainbow Manufacturers, Rajkot, India) and a tunnel is created around the open end of the bag to thread the ureteral catheter with the nylon thread. For specimen entrapment the device is inserted through the working port; after specimen placement into the bag the ureteral catheter is removed and the nylon thread used to tight the bag. The authors found the device easy to make and to be deployed, effective in removing the surgical specimen, with a low cost. However, attention should be made to the lack of permeability tests and stability tests and it should not be used for morcellation (5).

\section{Alternative Entrapment Devices}

Various approaches for benign specimen entrapment have been described in the literature. Raj et al. described an inexpensive alternative to specific specimen retrieval devices that achieves the same benefits but with very low cost. The new and low cost device utilizes a regular sterile latex glove with fingers extremities removed thus creating a latex bag. This approach is a good alternative to specific retrieval devices that are usually expensive; however in the setting of oncologic disease treatment it should not be used due to the fragility of the sack and easy rupture with potential tumor seeding (6).

Different techniques have been proposed for intact organ retrieval with the objective of reducing cost and simplifying material management. Terai et al. describe a simple technique using a heavy-duty polyethylene bag with a zip (normally used for food storage) and the authors found no complications related to specimen entrapment or perforation of the bag with a very 
Table 1 - Laparoscopic specimen retrieval devices.

\begin{tabular}{|c|c|}
\hline Device & Characteristics \\
\hline LapSac® - Cook & $\begin{array}{l}\text { Sack made of nylon with polyurethane inner coating. } \\
\text { Low cost. } \\
\text { Needs to be folded and rolled for abdominal cavity insertion. } \\
\text { Fits most trocar sizes for insertion. } \\
\text { Not self opened, needs aid of more than one instrument. }\end{array}$ \\
\hline LapBag® - Bard-Angiomed & $\begin{array}{l}\text { Sack made of nylon with polyurethane inner coating. } \\
\text { Have special introducer, ready for easy insertion. } \\
\text { Needs } 10-13 \mathrm{~mm} \text { trocar for insertion. } \\
\text { Self opened sack neck ring. }\end{array}$ \\
\hline Extraction Bag® - Karl Storz & $\begin{array}{l}\text { Sack made of transparent polyurethane. } \\
\text { Have special introducer, ready for easy insertion. } \\
\text { Needs } 10-13 \mathrm{~mm} \text { trocar for insertion. } \\
\text { Self opened sack neck ring made of nitinol. }\end{array}$ \\
\hline Endobag® - Dexide & $\begin{array}{l}\text { Sack made of transparent polyurethane. } \\
\text { Have special introducer, ready for easy insertion. } \\
\text { Needs } 12-13 \mathrm{~mm} \text { trocar for insertion. } \\
\text { Self opened sack neck ring made of plastic, without any spring mecha- } \\
\text { nism. }\end{array}$ \\
\hline Endopouch $\circledast$ - Ethicon & $\begin{array}{l}\text { Sack made of transparent Medifilm } 810 \text {. } \\
\text { Have special introducer, ready for easy insertion. } \\
\text { Needs } 12-13 \mathrm{~mm} \text { trocar for insertion. } \\
\text { Not self opened sack neck ring. }\end{array}$ \\
\hline Endo-Cath® - Auto Suture & $\begin{array}{l}\text { Sack made of transparent polyurethane. } \\
\text { Have special introducer, ready for easy insertion. } \\
\text { Needs } 10-12 \mathrm{~mm} \text { trocar for insertion. } \\
\text { Self opened sack neck ring made of metal. }\end{array}$ \\
\hline
\end{tabular}

low cost and easily performed by any laparoscopic surgeon. However the authors have made an important observation of never using this material for morcellation because they are not leakproof or strong enough (7).

These alternative entrapment devices presented another important concern related to its primary purpose: they were not designed to be used with this indication; however they may be used as prototype of new devices that will be specially designed for surgical and medical purpose.

\section{Specimen Retrieval}

Specimen retrieval after laparoscopic procedure varies according to surgical anatomic region, to the specimen removed and its size, the surgical purpose (malignant vs. benign disease) 
and if there is any other incision needed during surgery that could be used for this reason. The common extirpative Urologic surgical procedures include simple and radical nephrectomy, partial nephrectomy, nephroureterectomy, radical and simple prostatectomy, lymphadenectomy, adrenalectomy, orchiectomy, and extraction of urinary calculi.

We have previously reported a laparoscopic technique for large burden kidney stone, without the need of port site extension. A laparoscopic pyelolithotomy is performed in a standard manner and after the stone is removed from the renal pelvis, it is allocated inside an Endocatch device (U.S. Surgical; Norwalk, CT) and an ultrasonic lithotripter is used for stone fragmentation through a regular nephroscope, inside the peritoneal cavity. Stone fragments are removed along with the fluid aspiration. This technique is effective in completely remove the calculi, maintaining the procedure in a complete minimally invasive approach, with no increased complication rates (8).

Options at the termination of extirpative Urologic procedures include intact extraction and specimen morcellation. With intact extraction, specimen removal can be achieved by trocar site extension, connecting existing trocar site incisions, or by incising prior abdominal scars or creating a new incision. Transverse abdominal incisions are commonly chosen by surgeons because they achieve good cosmetics with potentially less pain if compared to incisions of other orientations (9). The use of retrieval devices facilitates either technique as with the Endocatch (U.S. Surgical; Norwalk, CT) for intact removal or the LapSac (Cook Urological; Spencer, IN) for the morcellated one. In a prospective study comparing the patient's impact from both retrieval techniques intact and morcellated, Gettman et al. found no significant differences in long term quality of life evaluation (10).

During extirpative procedures for malignant disease, there remains significant controversy regarding the acceptability of morcellation. Although it has been used for a long time in Urology, there are limited reports regarding tumor seeding or complications which have resulted from Urologic specimen morcellation (11-13). The decision to morcellate should be made in conjunction with the patient who must understand the risks and benefits of specimen morcellation.

Changes in skin incision have been also studied as alternative to a mini-laparotomy for large specimen retrieval. Casciola et al. described an umbilical trocar incision extension causing minimal aesthetic impact since this extension is kept hidden by the umbilical scar. The authors found this approach effective in surgical specimens with a great variability of shape and size, with or without the use of a laparoscopic retrieval device. The authors were able to retrieve considerable large specimens of up to 6 or $7 \mathrm{~cm}$, maintaining the minimally invasive advantages of laparoscopic surgery (14).

Some patients have the final cosmetic result as a major concern. To reduce abdominal scarification in women, specimen retrieval through a vaginal incision has been proposed in a reproducible technique, with excellent patient acceptance and satisfaction and low morbidity. However this technique should not be performed in young nulliparious women, patients with atrophic vaginitis, an extremely large specimen, vaginal infection or a vaginal prolapse, or in those in whom the cosmetic result is not a matter of concern $(15,16)$.

Supporters of intact specimen retrieval within an impermeable sack argument the superiority of this method due to the simplicity of extending a trocar-site incision or perform a Pfannenstiel incision, without compromising cosmetic or functional results. The intact specimen allows complete and more precise evaluation of tumor pathologic characteristics that may be adequately used for prognosis evaluation, guide oncologic follow-up, counseling and further adjuvant therapy $(17,18)$.

\section{Morcellation}

Laparoscopic urologic surgery started with Clayman et al. in 1991, performing radical nephrectomy (19). Initially, the fragmentation of organs in smaller pieces, known as morcellation, was used for specimen retrieval reducing abdominal wall incision extension. However, the proce- 
dure was soon surrounded by debates regarding safety and pathologic tissue examination.

Morcellated specimen retrieval is based on the sense of maintaining the minimally invasive characteristics of the laparoscopic procedure and the oncologic safety by performing it inside a sack, leak proof and strong enough to prevent perforation. The use of port-site wounds for organ morcellation and for the intact sack extraction containing the morcellated tissue is the rationale of this type of procedure. Other advantages besides the improved cosmetic result are an improvement in post-operative recovery due to the smaller incision, minimal skin wound and a lower risk of incisional hernia because there is reduced port-site manipulation and trauma (10).

In order to perform safe morcellation procedure, with reduced risk of tumor cell seeding it is necessary that the tissues are kept under direct or laparoscopic view with precise protection around the tissue, trocar and port-site through which the fragmented tissue will be retrieved. Before continuing with surgery, all equipment and surgical instruments, gowns and gloves need to be changed at the end of the morcellation procedure. Safe morcellation without tissue spillage or entrapment bag perforation have been achieved with the use of the LapSac or EndoCatch II sack. These sacks have proved to be made of impermeable materials preventing tissue and cell dissemination $(20,21)$.

Besides all debate and critics around morcellation procedure, there have been a limited number of case reports with of seeding after this procedure. Possible contributor factors for these recurrences are the fact of not using a sack specifically designed for morcellation and unrecognized microperforations in the sack. However this is a rare complication, with only a few reported cases in the literature (11). Another disadvantage is the impossibility of an adequate pathologic tumor staging that may impact on the ability to enroll patients in clinical chemotherapy trials and adequate oncologic follow-up.

Oncologic disease staging may be achieved based on radiologic imaging since computed tomography or magnetic resonance images have good accuracy; however they may under- or overstage tumors in $5 \%$ to $35 \%$ of cases (22).
Long-term studies evaluating oncologic results of morcellation have shown that this technique did not significantly impact the ability to detect pT3 disease and that there are no significant differences on recurrence-free, cancer specific or overall survival. Recurrence rates are similar to intact specimen retrieval, with similar oncological outcomes (23).

In vitro evaluation of pathologic assessment of morcellated specimen revealed that staging information was similar to that obtained from intact specimen retrieval; however these data have not been reproduced in the clinical setting (24).

Clinical pathologic staging after morcellation may be improved by removing larger fragments through a small extension on skin incision (25). Important pathologic characteristics for prognosis such as microvascular invasion can also be evaluated in morcellated fragments.

In the setting of keeping the procedure in a minimally invasive approach, morcellation enables specimen retrieval without enlargement of skin incision, with less post-operative pain and lower risk of incisional-related complications (26).

\section{Port-site fascial closure}

Deep port-site closure should comprise fascial reapproximation and deep subcutaneous suture in order to eliminate subcutaneous dead space, decreasing wound tension and maximizing skin edge eversion (27).

Hernia is a major concern in laparoscopic surgery since the trocar created wounds that are large enough to allow the bowel or omentum through it. Closure of fascial defects is quite difficult and frequently incomplete due to the small length of the skin incision.

Various different techniques and devices have been developed to aid the port-site fascial closure. Table- 2 shows a brief description of these techniques, divided into three major groups.

A maneuver that facilitates deep fascial wounds suture of port-sites is the maintenance of the pneumoperitoneum during closure in order to maintain a safe distance from the abdominal 
Table 2 - Laparoscopic fascial wound closure techniques.

\begin{tabular}{|c|c|c|}
\hline Technique & Characteristic & Example \\
\hline $\begin{array}{l}\text { Closure assisted from inside abdomen } \\
\text { (i.e., requiring two additional ports: } \\
\text { one for the laparoscope and one for the } \\
\text { grasper) }\end{array}$ & $\begin{array}{l}\text { Instrument manipulation is done under } \\
\text { direct visualization, allowing higher safety } \\
\text { in avoiding visceral injuries. }\end{array}$ & $\begin{array}{l}\text { Maciol needles; Grice needle; Use of ca- } \\
\text { theter or spinal needles; The Endoclose } \\
\text { device; The Gor-Tex device. }\end{array}$ \\
\hline $\begin{array}{l}\text { Closure assisted by the use of extracor- } \\
\text { poreal instruments (i.e., needing only } \\
\text { one additional port for the laparoscope). }\end{array}$ & $\begin{array}{l}\text { Suture is performed extracorporeally } \\
\text { under intra-abdominal direct visualization } \\
\text { by the laparoscope. One of the most used } \\
\text { techniques. }\end{array}$ & $\begin{array}{l}\text { Carter-Thomason CloseSure System; } \\
\text { Endo-Judge wound closure device; } \\
\text { Tahoe Surgical Instrument Ligature de- } \\
\text { vice; eXit Disposable Puncture Closure } \\
\text { device; The Closure techniques using a } \\
5 \text { or } 2 \mathrm{~mm} \text { trocar. }\end{array}$ \\
\hline $\begin{array}{l}\text { Closure performed with or without } \\
\text { visual control. }\end{array}$ & $\begin{array}{l}\text { Suture aided by a tactile sense, applicable } \\
\text { during insufflation or after desufflation. }\end{array}$ & $\begin{array}{l}\text { Suture carrier; The dualhemostat tech- } \\
\text { nique; The Lowsley retractor; Reverdin } \\
\text { needle; Deschamps needle; Standard } \\
\text { technique of hand-sutured closure. }\end{array}$ \\
\hline
\end{tabular}

wall to the bowel and other viscera. Another advantage of maintaining the pneumoperitoneum is that it enables surgeon inspection of abdominal cavity through smaller ports regarding adequate fascial wound closure, haemostasis and that any viscera is implicated in the suture (28).

\section{Improving fascial port-site wound closure}

Simple and more economic methods of laparoscopic port-site wound closure have been described as the use of a Foley catheter for the closure of 10-12 mm wounds. The Foley catheter allows for abdominal wall traction with easy wound evaluation to avoid any trapped viscera, while the inflated balloon may prevent herniation of the omentum or bowel through port-site defect. This method showed no significant difference in operative time, postoperative pain and complication rate if compared to traditional suturing closure, while has demonstrated to be easy to apply, not expensive, without the need for special training or having to handle a new instrument (29).
Another technique that has been described for port-site closure is by using a hemostat clamp for suture guidance. The hemostat is used to grasp the peritoneum and rectus sheath of both incision edges under direct laparoscopic view followed by deflation of the pneumoperitoneum and standard suturing of the wound edges (30).

\section{Port-site skin closure}

Port-site skin wounds may be closed in a wide variety of techniques, applying different kinds of sutures and materials (Table-3).

Buchweitz et al., in a prospective randomized study, assessed the outcome of $5 \mathrm{~mm}$ laparoscopic port site skin closure by three different techniques. The authors found that patient's cosmetic satisfaction was higher with the use of transcutaneously sutured wounds compared to the subcutaneous suturing or the use of papertape closure. The authors attributed the improved cosmetics with the transcutaneous suture to the better coaptation of skin edges, enabling a higher quality scar result (31). 
Table 3 - Skin closure methods.

\begin{tabular}{|c|c|c|c|}
\hline Subcuticular continuous suture & $\begin{array}{l}\text { Provides excellent skin } \\
\text { edge apposition. }\end{array}$ & $\begin{array}{l}\text { There are no external } \\
\text { sutures or cross- } \\
\text {-hatching. }\end{array}$ & $\begin{array}{l}\text { May be an absorbable suture, such as } \\
\text { polyglactic } 910 \text { (Vicryl®) or poligle- } \\
\text { caprone (Monocryl®), or a nonabsor- } \\
\text { bable suture, such as polypropylene } \\
\text { (Prolene®). }\end{array}$ \\
\hline $\begin{array}{l}\text { Tissue Adhesives - 2-0ctylcyanoa- } \\
\text { crylate (Dermabond } ®)\end{array}$ & $\begin{array}{l}\text { Strong and flexible me- } \\
\text { thod of approximating } \\
\text { wound edges. }\end{array}$ & $\begin{array}{l}\text { Should be applied to } \\
\text { intact skin at wound } \\
\text { edge to hold the injured } \\
\text { surfaces together. }\end{array}$ & $\begin{array}{l}\text { Particularly useful in superficial } \\
\text { wounds or wounds in which the deep } \\
\text { dermis has been closed with sutures. }\end{array}$ \\
\hline Skin Tapes & $\begin{array}{l}\text { Closure with micro- } \\
\text { porous tape produces } \\
\text { more resistance to } \\
\text { infection. }\end{array}$ & $\begin{array}{l}\text { Maintain the integrity of } \\
\text { the epidermis, resulting } \\
\text { in less tension to the } \\
\text { wound. } \\
\text { If used over sutures } \\
\text { tape can relieve tension } \\
\text { at the wound edges. }\end{array}$ & $\begin{array}{l}\text { Linear wounds in areas with little } \\
\text { tension are easily approximated with } \\
\text { tape alone. }\end{array}$ \\
\hline
\end{tabular}

The use of skin adhesives associated to traditional suture provides extra closure support with an impermeable suture line, decreasing the need for postoperative care. It is especially interesting to use in pediatric patients since there is no need of postoperative suture removal (32).

\section{Skin adhesives}

Cyanoacrylate based glues are fast-acting adhesives formed by an association of a monomer and a plasticizer that forms a flexible bond presenting a breaking strength comparable to that of 5-0 monofilament suture and the intent of its use is to achieve good skin edges coaptation, just as it is done with the traditional sutures. It sets quickly, usually under $1 \mathrm{~min}$, a characteristic that enables it an easy to use technology in small incisions such as traumatic skin lacerations and laparoscopic port-site wounds (33).

Advantages of the use of skin adhesives are the formation of a watertight barrier that allow patients to shower any time after surgery, enabling a more adequate recovering from surgery and high patient acceptance. Other possible bene- fit that may rise from the use of these adhesives is a decrease in the use of needled sutures reducing personal needle exposure in the operating room.

Major disadvantages of the use of OCA are the need of a learning curve since it has some particularities for application as the need of a dry surface, with good edge-to-edge approximation. This technique is necessary in order to avoid the substance within the incision, since its presence will cause an intense foreign body reaction leading to a not acceptable final skin cosmetics. Cost is another matter of concern to the use of these skin adhesives, when compared to the cost of traditional sutures $(33,34)$.

Available literature data comparing tissue adhesives and traditional subcutaneous suture for port-site closure revealed that skin adhesives are well accepted by patients due to its good final cosmetic skin result and to the fact that causes less pain with no need of suture removal. Surgeons satisfaction with the use of these kind of adhesives are due to a faster skin closure time and to the finding of similar complication rate of wound infection and dehiscence to that of traditional sutures. However an important issue regarding the 
skin adhesives usage is the high cost, when compared to suture closure of port-site wounds - each vial of adhesive may cost three times or more the cost of a suture, estimated for a same length incision $(34,35)$.

\section{Port-site Hernia formation}

Hernia formation at the site of a laparoscopic trocar is not frequent but is a deleterious complication since it is likely to require a new surgical procedure in order to correct the abdominal wall defect $(36,37)$.

Different characteristics may help to classify an incisional hernia as the time from surgery that it occurred, if there is any content from abdominal cavity trapped inside of it, if there is any functional consequence as bowel obstruction or pain. These properties will guide surgeon's decision to observe or to recommend a new intervention in an elective or emergency setting (38).

Reasons contributing to the development of an incisional hernia at a laparoscopic trocarport may be early suture disruption, skin or subcutaneous infection, patient malnutrition status, patient's early return to daily activities or failure to adequately reapproximate fascial wound edges.

There is an inherent fascial weakness at the paraumbilical region, leading to a higher incidence on hernia formation. Midline trocars are also associated with a higher incidence of this complication, probably due to the fact that these trocars are usually of larger size and are actively manipulated during the surgical procedure. Umbilical and midline trocars are also frequently used for organ retrieval, seriously influencing fascial tissue trauma and weakness, predisposing to hernia formation $(37,39)$.

Lateral port-sites usually have a lower incidence on hernia formation, due to the presence of multiple abdominal wall muscular layers improving wound closure; still, frequently smaller size trocars are used at these sites, resulting in smaller wound defects (40).

It is recommended to end the pneumoperitoneum completely before closing the trocar port wounds, in order to prevent intestine or omentum herniation due to gas pushing (37).
Trocar diameter is associated to the development of an incisional hernia at trocar wound, presenting a proportional risk to the trocar size. After laparosocopic surgery all 10 and $12 \mathrm{~mm}$ trocar sites are best treated if properly closed, with adequate fascial wound edges suture and coaptation. Regarding the $5 \mathrm{~mm}$ trocar fascia closure, there has been some arguing on the matter, especially in pediatric population (41). In general, authors advocate that all trocar wounds in the pediatric population should be closed, while in the adult patients they recommend closing all trocars larger than $5 \mathrm{~mm}(42,43)$.

\section{Prophylatic Drainage}

Prophylactic abdominal drainage at the beginning of the 1900's had became a major concern and was not routinely recommended. Yates after an experimental study had stated in 1905 that "drainage of the peritoneal cavity is physically and physiologically impossible" (44). Drainage had presented so many complications that in 1919 Frank Hathaway wrote "Its day is past, and soon it will only be seen, where it should be, in a museum" in his article about abuse of drainage tubes (45).

There is enough evidence in the literature not to recommend prophylactic abdominal drainage in all abdominal procedures, being unnecessary or even harmful (46). In some cases, the use of drains may even be related to longer hospital stay and higher postoperative morbidity (47).

The rational for abdominal cavity drainage is based on the fact that the presence of gas or fluid in the peritoneal cavity may disrupt inflammatory reaction leading clinically to an increase of complications as pain and infection $(48,49)$. Other reasons for drainage placement after a surgical procedure are any doubt about potential complication as difficulty in obtaining hemostasis or any vessel ligation, intestine suture that the surgeon was not totally confident with the result and even problematic or difficult urinary tract closure (50).

There are two basic differences regarding drain characteristics: they may be set in a closed or open system and with or without suction. 


\section{Urologic Laparoscopy Drainage}

The improvement of techniques and development of new instruments along with the fact of laparoscopic expertise being achieved by many surgeons made the number of partial nephrectomies to grow and surgical indications expanded to larger and deeply located tumors, with a higher frequency of collecting system involvement (51). As well it enables the use of this technique for Radical Prostatectomy in the treatment of prostate cancer, with comparable results to the standard retropubic open surgery (52). However with an increase in the frequency of this surgical approach it is expected to find also an increase in the number of complications $(53,54)$.

Laparoscopic surgery has been successfully introduced in the treatment of urinary tract stone disease, with major applications for ureteral calculli and treatment of Ureteropelvic junction (UPJ) anomaly or caliceal diverticula $(55,56)$.

The most frequent surgical complications after laparoscopic urologic procedures include bleeding, hematomas, urine leak, and infection. The use of a drainage system enables early diagnosis of any of these conditions allowing fast intervention in order to adequately treat the com- plication. Commonly urologic procedures that may require drainage are listed in Table-4.

Urine leak risk factors are associated to tumor size, tumor endophytic location and the need to open the collecting system during surgery. The majority of urine leak cases were successfully treated by prolonged drainage and drain manipulation. When non invasive treatment achieved unsuccessful urine leak resolution, treatment including ureteral stenting should be done being highly effective (57). It is only in cases where conservative maneuvers were not efficacious in achieving resolution that open repair or even nephrectomy may be necessary.

\section{Drainage after Robotic Surgery}

Indication for drainage after radical prostatectomy are usually tension at the urethrovesical anastomosis, bladder neck deformity, a large median lobe, rectal injury, urinary bladder injury, and need to redo urethrovesical anastomosis. Other potential complications related to abdominal wall drain insertion are muscle or subcutaneous hematoma, pain at the drain site, injury to the inferior epigastric vessels, and loss of part of the drain inside the abdominal cavity. Potential

Table 4 - Urologic laparoscopic drainage.

\begin{tabular}{|c|c|}
\hline Procedure & Drainage \\
\hline Nephrectomy & $\begin{array}{l}\text { Needs drainage if there is doubt about bleeding or extensive } \\
\text { linfonode dissection. }\end{array}$ \\
\hline Partial Nephrectomy & $\begin{array}{l}\text { Always drain due to kidney's resection bed and possible or } \\
\text { needed opening of the collecting system. }\end{array}$ \\
\hline Lymphadenectomy & Drain if extensive dissection due to the higher risk of lymphocele. \\
\hline Radical Prostatectomy & $\begin{array}{l}\text { Routinely require drainage to observe urethrovesical anas- } \\
\text { tomosis. There is some debate when surgery is done with } \\
\text { magnification and result in a watertight anastomosis. }\end{array}$ \\
\hline Adrenalectomy & $\begin{array}{l}\text { Usually does not require drainage. Recommended if any con- } \\
\text { cerns about bleeding. }\end{array}$ \\
\hline Stone disease/Pyeloplasty & $\begin{array}{l}\text { Drainage required due to urinary tract opening and the aug- } \\
\text { mented risk of urinary leak. }\end{array}$ \\
\hline
\end{tabular}


urinary complications that may arise from drain omission after radical prostatectomy are usually the development of collection of urine, anastomotic stricture due to urine leak, lymphoceles and urinary incontinence.

In a recent study Canes et al. evaluated the existence of an association between pelvic drainage and postoperative complications on patients who underwent laparoscopic radical prostatectomy. The authors found that drainage resulted in longer operative times and greater narcotic use if compared to undrained patients. Regarding other complications there was no increase of clinically detected urine leak, collection of urine, hematoma or lymphocele. Although routine pelvic drainage is usually part of the radical prostatectomy procedure, these findings support the possibility of drain omission when a urethrovesical anastomosis is watertight during the intraoperative test (58). This approach reduces hospital stay and costs, and has been demonstrated to be safe with no rise in the complication rates (59).

The improved technology led to some debate whether a drain is really necessary after partial nephrectomy. Robotic assisted partial nephrectomy demonstrated the ability to reduce blood loss, operative time and warm ischemia time when compared to pure laparoscopic partial nephrectomy (60). Closure of the collecting system may be improved through the use of robotic technology in laparoscopic renal surgery resulting in a decrease of the urine leak frequency. Perhaps in the future the technologic improvement with safer and watertight closure of the collecting system will enable surgeons to elude the use of drains in those situations.

\section{Open Passive Versus Closed Drainage}

Skin wound and abdominal wall trajectory of Penrose drainage works as an entrance door for bacterial colonization and migration, in a higher frequency than when using closed suction drains (61,62).

Multiple drainage systems were developed to be use as a closed system, either with or without suction, with efficacy on removing fluid from the abdominal cavity after laparoscopic surgery (63).
A closed drainage system is achieved when the drain insertion is performed in a way to be water and air tight, precluding external contact to the drained cavity. It may be inserted and used in a passive way, allowing drainage mostly of liquid fluid material. When the material to be drained is a thicker fluid it is advisable to add a suction system in order to facilitate drainage.

Closed suction drains have been avoided by Urologists due to the potential risk of prolonged urinary drainage that has been expressed in the statement "Penrose drains should be used in all patients because closed suction drains can perpetuate" and by perpetuating we should understand as a urinary fistula or even a delayed hemorrhage after drain removal (64). However we have enough data to make this orientation differently since many have successfully used closed suction drains after urologic laparoscopic surgery, finding it effective, with no increased morbidity (65).

In a comparison of suction and non-suction drains there was similar pain scores associated to the period before or after drain removal. The removal procedure is usually more painful when the drain used is of suction type, probably due to soft early adherences of small bowel or omentum to the drain tube holes (66).

Data obtained from general surgery literature have been able to clearly demonstrate that closed suction drains are associated with fewer complications when compared to an open passive drain as the Penrose one (67).

\section{CONFLICT OF INTEREST}

None declared.

\section{REFERENCES}

1. Rajan $P$, Turna $B$ : New trends in minimally invasive urological surgery. Int Braz J Urol. 2009; 35: 514-20.

2. Rassweiler J, Stock C, Frede T, Seemann 0, Alken P: Organ retrieval systems for endoscopic nephrectomy: a comparative study. J Endourol. 1998; 12: 325-33.

3. Iwamura M, Tsumura H, Matsuda D, Kurosaka S, Yoshida K, Baba S: Port site recurrence of renal cell carcinoma following retroperitoneoscopic radical nephrectomy with manual extraction without using entrapment sac or wound protector. J Urol. 2004; 171: 1234-5. 
4. Ankem MK, Hedican SP, Pareek G, Waterman BJ, Moon TD, Selvaggi SM, et al.: Examination of laparoscopic retrieval bag washings for malignant cells after hand-assisted laparoscopic radical nephrectomy and intact specimen removal. Urology. 2006; 68: 50-2.

5. Ganpule AP, Gotov E, Mishra S, Muthu V, Sabnis R, Desai M: Novel cost-effective specimen retrieval bag in laparoscopy: Nadiad bag. Urology. 2010; 75: 1213-6.

6. Raj PK, Katris F, Linderman CG, ReMine SG: An inexpensive laparoscopic specimen retrieval bag. Surg Endosc. 1998; 12: 83.

7. Terai A, Ichioka K, Inoue K, Yoshimura K: A simple kidney entrapment technique using a zipped plastic bag during retroperitoneoscopic radical nephrectomy. BJU Int. 2005; 96: 683-4.

8. Collins S, Marruffo F, Durak E, Hruby G, Bergman A, Gupta $M$, et al.: Laparoscopic pyelolithotomy with intraperitoneal ultrasonic lithotripsy: report of a novel minimally invasive technique for intracorporeal stone ablation. Surg Laparosc Endosc Percutan Tech. 2006; 16: 435-6.

9. Tisdale BE, Kapoor A, Hussain A, Piercey K, Whelan JP: Intact specimen extraction in laparoscopic nephrectomy procedures: Pfannenstiel versus expanded port site incisions. Urology. 2007; 69: 241-4.

10. Gettman MT, Napper C, Corwin TS, Cadeddu JA: Laparoscopic radical nephrectomy: prospective assessment of impact of intact versus fragmented specimen removal on postoperative quality of life. J Endourol. 2002; 16: 23-6.

11. Castillo OA, Vitagliano G: Port site metastasis and tumor seeding in oncologic laparoscopic urology. Urology. 2008; 71: 372-8.

12. Fentie DD, Barrett PH, Taranger LA: Metastatic renal cell cancer after laparoscopic radical nephrectomy: long-term follow-up. J Endourol. 2000; 14: 407-11.

13. Castilho LN, Fugita OE, Mitre Al, Arap S: Port site tumor recurrences of renal cell carcinoma after videolaparoscopic radical nephrectomy. J Urol. 2001; 165: 519.

14. Casciola L, Codacci-Pisanelli M, Ceccarelli G, Bartoli A, Di Zitti L, Patriti A: A modified umbilical incision for specimen extraction after laparoscopic abdominal surgery. Surg Endosc. 2008; 22: 784-6.

15. Gill IS, Cherullo EE, Meraney AM, Borsuk F, Murphy DP, Falcone T: Vaginal extraction of the intact specimen following laparoscopic radical nephrectomy. J Urol. 2002; 167: 238-41.

16. Ghezzi F, Raio L, Mueller MD, Gyr T, Buttarelli M, Franchi M: Vaginal extraction of pelvic masses following operative laparoscopy. Surg Endosc. 2002; 16: 1691-6.

17. Novick AC: Laparoscopic radical nephrectomy: specimen extraction. BJU Int. 2005; 95(Suppl 2): 32-3.

18. Kaouk JH, Gill IS: Laparoscopic radical nephrectomy: morcellate or leave intact? Leave intact. Rev Urol. 2002; 4: 38-42.
19. Clayman RV, Kavoussi LR, Soper NJ, Dierks SM, Merety KS, Darcy MD, et al.: Laparoscopic nephrectomy. N Engl J Med. 1991; 324: 1370-1.

20. Wu SD, Lesani OA, Zhao LC, Johnston WK, Wolf JS Jr, Clayman RV, et al.: A multi-institutional study on the safety and efficacy of specimen morcellation after laparoscopic radical nephrectomy for clinical stage $\mathrm{T} 1$ or $\mathrm{T} 2$ renal cell carcinoma. J Endourol. 2009; 23: 1513-8.

21. Varkarakis I, Rha K, Hernandez F, Kavoussi LR, Jarrett TW: Laparoscopic specimen extraction: morcellation. BJU Int. 2005; 95(Suppl 2): 27-31.

22. Rabban JT, Meng MV, Yeh B, Koppie T, Ferrell L, Stoller $M L$ : Kidney morcellation in laparoscopic nephrectomy for tumor: recommendations for specimen sampling and pathologic tumor staging. Am J Surg Pathol. 2001; 25: 1158-66.

23. Gabr AH, Gdor Y, Strope SA, Roberts WW, Wolf JS Jr.: Approach and specimen handling do not influence oncological perioperative and long-term outcomes after laparoscopic radical nephrectomy. J Urol. 2009; 182: 874-80.

24. Landman J, Lento P, Hassen W, Unger P, Waterhouse R: Feasibility of pathological evaluation of morcellated kidneys after radical nephrectomy. J Urol. 2000; 164: 2086-9.

25. Landman J, Venkatesh R, Kibel A, Vanlangendonck R: Modified renal morcellation for renal cell carcinoma: laboratory experience and early clinical application. Urology. 2003; 62: 632-4; discussion 635.

26. Camargo AH, Rubenstein JN, Ershoff BD, Meng MV, Kane CJ, Stoller ML: The effect of kidney morcellation on operative time, incision complications, and postoperative analgesia after laparoscopic nephrectomy. Int Braz J Urol. 2006; 32: 273-9; discussion 279-80.

27. Toriumi DM, O'Grady K, Desai D, Bagal A: Use of octyl2-cyanoacrylate for skin closure in facial plastic surgery. Plast Reconstr Surg. 1998; 102: 2209-19.

28. Shaher Z: Port closure techniques. Surg Endosc. 2007; 21: 1264-74.

29. Su WH, Cheng MH, Tsou TS, Cheung SM, Chang SP, Wang PH: Port wound closure assisted by Foley catheter: an easier way to provide fascia security. J Obstet Gynaecol Res. 2009; 35: 725-31.

30. Rastogi V, Dy V: Simple technique for proper approximation and closure of peritoneal and rectus sheath defects at port site after laparoscopic surgery. J Laparoendosc Adv Surg Tech A. 2001; 11: 13-6.

31. Buchweitz 0 , Wülfing $P$, Kiesel $L$ : A prospective randomized trial of closing laparoscopic trocar wounds by transcutaneous versus subcuticular suture or adhesive papertape. Surg Endosc. 2005; 19: 148-51.

32. Hochberg J, Meyer KM, Marion MD: Suture choice and other methods of skin closure. Surg Clin North Am. 2009; 89: $627-41$. 
33. Sebesta MJ, Bishoff JT: Octylcyanoacrylate skin closure in laparoscopy. J Endourol. 2003; 17: 899-903.

34. Matin SF: Prospective randomized trial of skin adhesive versus sutures for closure of 217 laparoscopic port-site incisions. J Am Coll Surg. 2003; 196: 845-53.

35. Sajid MS, Siddiqui MR, Khan MA, Baig MK: Meta-analysis of skin adhesives versus sutures in closure of laparoscopic portsite wounds. Surg Endosc. 2009; 23: 1191-7.

36. Callery MP, Strasberg SM, Soper NJ: Complications of laparoscopic general surgery. Gastrointest Endosc Clin N Am. 1996; 6: 423-44.

37. Azurin DJ, Go LS, Arroyo LR, Kirkland ML: Trocar site herniation following laparoscopic cholecystectomy and the significance of an incidental preexisting umbilical hernia. Am Surg. 1995; 61: 718-20.

38. Tonouchi H, Ohmori Y, Kobayashi M, Kusunoki M: Trocar site hernia. Arch Surg. 2004; 139: 1248-56.

39. Tisdale BE, Kapoor A, Hussain A, Piercey K, Whelan JP: Intact specimen extraction in laparoscopic nephrectomy procedures: Pfannenstiel versus expanded port site incisions. Urology. 2007; 69: 241-4.

40. Bird VG, Au JK, Sandman Y, De Los Santos R, Ayyathurai R, Shields JM: Comparison of different extraction sites used during laparoscopic radical nephrectomy. J Urol. 2009; 181: 1565-70.

41. Spalding SC, Ponsky TA, Oristian E: A new Dual-hemostat technique to facilitate the closure of small laparoscopic trocar incisions. Surg Endosc. 2003; 17: 164-5.

42. Sanz-López R, Martínez-Ramos C, Núñez-Peña JR, Ruiz de Gopegui M, Pastor-Sirera L, Tamames-Escobar S: Incisional hernias after laparoscopic vs open cholecystectomy. Surg Endosc. 1999; 13: 922-4.

43. Kulacoglu IH: Regarding: Small bowel obstruction and incisional hernia after laparoscopic surgery: should 5-mm trocar sites be sutured? J Laparoendosc Adv Surg Tech A. 2000; 10: 227-8.

44. Yates JL: An experimental study of the local effects of peritoneal drainage. Surg Gynecol Obstet. 1905; 1: 473-92.

45. Hathaway F: The Abuse of Drainage Tubes. Br Med J. 1918; 1: 718-20.

46. Petrowsky H, Demartines N, Rousson V, Clavien PA: Evidencebased value of prophylactic drainage in gastrointestinal surgery: a systematic review and meta-analyses. Ann Surg. 2004; 240: 1074-84; discussion 1084-5.

47. de Rougemont 0, Dutkowski P, Weber M, Clavien PA: Abdominal drains in liver transplantation: useful tool or useless dogma? A matched case-control study. Liver Transpl. 2009; 15: 96-101.

48. Abbott J, Hawe J, Srivastava P, Hunter D, Garry R: Intraperitoneal gas drain to reduce pain after laparoscopy: randomized masked trial. Obstet Gynecol. 2001; 98: 97-100.
49. Shen CC, Huang FJ, Hsu TY, Weng HH, Chang HW, Chang SY: A prospective, randomized study of closed-suction drainage after laparoscopic-assisted vaginal hysterectomy. J Am Assoc Gynecol Laparosc. 2002; 9: 346-52.

50. Tzovaras G, Liakou P, Fafoulakis F, Baloyiannis I, Zacharoulis $D$, Hatzitheofilou $C$ : Is there a role for drain use in elective laparoscopic cholecystectomy? A controlled randomized trial. Am J Surg. 2009; 197: 759-63.

51. Simmons MN, Gill IS: Decreased complications of contemporary laparoscopic partial nephrectomy: use of a standardized reporting system. J Urol. 2007; 177: 2067-73; discussion 2073.

52. Bove P, Asimakopoulos AD, Kim FJ, Vespasiani G: Laparoscopic radical prostatectomy: a review. Int Braz J Urol. 2009; 35: 125-37; discussion 137-9.

53. Richstone L, Montag S, Ost M, Reggio E, Permpongkosol S, Kavoussi LR: Laparoscopic partial nephrectomy for hilar tumors: evaluation of short-term oncologic outcome. Urology. 2008; 71: 36-40.

54. Permpongkosol S, Link RE, Su LM, Romero FR, Bagga HS, Pavlovich CP, et al.: Complications of 2,775 urological laparoscopic procedures: 1993 to 2005. J Urol. 2007; 177: 580-5.

55. Micali S, Moore RG, Averch TD, Adams JB, Kavoussi LR: The role of laparoscopy in the treatment of renal and ureteral calculi. J Urol. 1997; 157: 463-6.

56. Nambirajan T, Jeschke S, Albqami N, Abukora F, Leeb K, Janetschek G: Role of laparoscopy in management of renal stones: single-center experience and review of literature. J Endourol. 2005; 19: 353-9.

57. Meeks JJ, Zhao LC, Navai N, Perry KT Jr, Nadler RB, Smith ND: Risk factors and management of urine leaks after partial nephrectomy. J Urol. 2008; 180: 2375-8.

58. Canes D, Cohen MS, Tuerk IA: Laparoscopic radical prostatectomy: omitting a pelvic drain. Int Braz J Urol. 2008; 34: 151-8.

59. Sharma S, Kim HL, Mohler JL: Routine pelvic drainage not required after open or robotic radical prostatectomy. Urology. 2007; 69: 330-3.

60. Benway BM, Bhayani SB, Rogers CG, Dulabon LM, Patel MN, Lipkin M, et al.: Robot assisted partial nephrectomy versus laparoscopic partial nephrectomy for renal tumors: a multiinstitutional analysis of perioperative outcomes. J Urol. 2009; 182: 866-72.

61. Nora PF, Vanecko RM, Bransfield JJ: Prophylactic abdominal drains. Arch Surg. 1972; 105: 173-6.

62. Raves JJ, Slifkin M, Diamond DL: A bacteriologic study comparing closed suction and simple conduit drainage. Am J Surg. 1984; 148: 618-20.

63. Chan K, Welsh A, Abbott J: Suction versus non-suction drains to remove fluid from the pelvis following gynecological laparoscopy: A RCT. Obstet Gynecol. 2008; 111: 293-7. 
64. Naitoh J, Smith R: Complications of renal surgery. In: Complications of Urologic Surgery. Taneja SS, Smith RB, Ehrlich RM (ed.), Philadelphia: W.B. Saunders Co. 2001. pp. 299-325.

65. Chan DY, Marshall FF: Partial nephrectomy for centrally located tumors. Urology. 1999; 54: 1088-91; discussion 1091-2.

66. Raymond AP, Chan K, Deans R, Bradbury R, Vancaillie TG, Abbott JA: A comparative, single-blind, randomized trial of pain associated with suction or non-suction drains after gynecologic laparoscopy. J Minim Invasive Gynecol. 2010; 17: 16-20.
67. Sánchez-Ortiz R, Madsen LT, Swanson DA, Canfield SE, Wood CG: Closed suction or penrose drainage after partial nephrectomy: does it matter? J Urol. 2004; 171: 244-6.

Correspondence address: Dr. Ricardo A. Natalin Universidade Federal de Sao Paulo - Brazil Av. Sena Madureira, 1500 - $5^{\circ}$ andar Sao Paulo, SP, 04021-001, Brazil E-mail: ricardonatalin@yahoo.com.br 